that four showed regression of radiological abnormalities during treatment. Even more impressive were the results from the children's hospital in Lund, where 10 out of 11 children went into prolonged remission with healing of ulcers and fistulae. ${ }^{12}$ Though the dose was high (3-4 $\mathrm{g}$ daily) side effects were uncommon.

Unwanted actions are a major limitation of therapy in adults, in whom they usually occur in the first few weeks of treatment. ${ }^{413}$ They may sometimes be prevented by starting treatment at a low dose which is increased after a few days. Gastrointestinal symptoms may be overcome by using entericcoated tablets.

Methods of medical treatment for Crohn's disease have been remarkable for their lack of scientific assessment so that a recent international trial of sulphasalazine in Scandinavia is a major event. ${ }^{14}$ Unfortunately, the numbers were small, the treatment was of short duration, and the conclusions must be limited. Two groups of patients were studied by a double-blind double-crossover technique with four treatment periods of one month each. The first group contained 12 patients who had undergone surgical resection in the past and had subsequently developed symptoms suggesting recurrence of the disease; sulphasalazine therapy was not superior to the placebo. The second group consisted of 13 patients who had never been operated upon but had been complaining of symptoms for a longer period and had radiological confirmation of the diagnosis; treatment with sulphasalazine resulted in a significant reduction in symptoms. In both groups sulphasalazine therapy generally restored abnormal blood to normal tests with the exception of the haemoglobin concentration.

When should sulphasalazine be used in a patient with Crohn's disease? Patients should be given the minimum treatment that will control their symptoms and maintain their nutrition. Many patients require no specific therapy. When purely symptomatic treatment is not enough, it is now logical to try sulphasalazine before administering corticssteroids or azathioprine or embarking on surgery. The precise site of inflammation does not affect the response to treatment; disease of both the small and large intestine may respond. The indications for therapy are still far from settled, and more and better controlled trials are needed. It is not known if sulphasalazine is superior to other sulphonamides; sulphathalidine appears to have induced a remission in a single patient. ${ }^{15}$ Furthermore, there is no information on the optimum duration of treatment or the role of the drug in maintenance therapy, especially after resection of diseased bowel. The effects of sulphasalazine need to be compared with those of the broadspectrum antibiotics, which may also have a place in therapy. As so often in any form of treatment for Crohn's disease, it seems to be a case of trial and error without any formal trial.

1 Svartz, N., Acta Medica Scandinavica, 1942, 110, 577

2 Svartz, N., Acta Medica Scandinavica, 1942,1

3 Truelove, S. C., Watkinson, G., and Draper, G., British Medical fournal, $1962,2,1708$.

4 Misiewicz, J. J., et al., Lancet, 1965, 1, 185.

5 Dissanayake, A. S., and Truelove, S. C., Gut, 1973, 14, 923.

- Baron, J. H., et al., Lancet, 1962, 1, 1094.

7 Drug and Therapeutics Bulletin, 1966, 4, 90.

8 Dyer, N. H., Clinics in Gastroenterology, 1972, 1, 449.

Lennard-Jones, J. E., in Modern Trends in Gastroenterology, No. 4, ed. W. I. Card, and B. Creamer, p. 273, London, Butterworths, 1970.

10 Kyle, J., Crohn's Disease, London, Heinemann, 1972.

11 Goldstein, F., and Murdock, M. G., American fournal of Digestive Diseases, 1971, 16, 421 .

12 Meeuwisse, G. W., and Hansing, B., Acta Paediatrica, 1971, 60, 375.

13 Collins, J. R., Southern Medical fournal, 1968, 61, 354

14 Anthonisen, P., et al., Scandinavian fournal of Gastroenterology, 1974, 9, 549.

15 Jones, J. H., Lennard-Jones, J. E., and Young, A. C., Gut, 1969, 10, 738.

\section{Prinzmetal's Variant Angina}

In 1959 Prinzmetal with others described 32 patients with a variant form of angina ascribed to temporarily increased tonus in a major coronary artery. ${ }^{1}$ The Prinzmetal variant does not show the two major characteristics of classical angina: it is not precipitated by an increase in cardiac work, nor is it associated with ST segment depression on the E.C.G. During the pain, the E.C.G. shows a definite rise in the ST segments in the territory of a major coronary artery with reciprocal ST depression in opposite leads. The patients can often exercise freely without any chest discomfort or change in the E.C.G. ${ }^{2} 3$

Recently, interest has developed in coronary spasm as the possible cause of atypical angina in both patients with normal coronary arteries and those with normal or abnormal coronary arteries who display the variant angina syndrome. ${ }^{3-8}$ Coronary spasm with ST elevation has been seen in patients with marked obstructive disease of their coronary arteries who may also develop angina of effort with ST segment depression. In the typical Prinzmetal syndrome attacks occur almost exclusively at rest, being elicited neither by bicycle ergometry nor by atrial pacing; and while the ST elevation on the E.C.G. suggests subepicardial ischaemia or impending infarction the amount of coronary artery disease usually found on investigation in no way accounts for the severity of the clinical phenomena. The coronary spasm which Prinzmetal postulated to explain these attacks seems to be real, but it has been difficult to prove. Coronary spasm has often been seen during angiography in patients who showed no features of the Prinzmetal variant, but since most angiograms are carried out by direct intubation the spasm was thought to be catheter induced. Many cardiac laboratories routinely give sublingual nitroglycerin before coronary angiography ${ }^{9}$ and so never see spasm. Others tend to investigate the patient using diazepam or other sedation, which might keep spasm at bay.

Patients with Prinzmetal angina may be severely incapacitated or die, and medical treatment is unsatisfactory. Coronary bypass grafting has not usually been recommended because the recipe for success seems to depend on the combination of severe obstruction in the native coronary artery with a free conduit down the graft : division of flow between the alternative pathways might be conducive to thrombosis. The results of surgery in patients with this condition have been poor unless the site of spasm could be positively identified, ${ }^{8}$ and the graft patency rate has been low. ${ }^{3}$ Surgery may be successful, however: in one patient with a $60 \%$ stenosis in the main right coronary artery and Prinzmetal's angina a graft cured distressing symptoms. Post operative angiography showed the graft to be patent, and when gross spasm developed in the proximal right coronary artery flow into its distal territory was maintained by the vein graft, and the patient developed neither symptoms nor E.C.G. changes. ${ }^{9}$

Surgery must be indicated only rarely, because of the difficulty in knowing whether the spasm always occurs in the same place, but in patients in whom spasm seems to occur at the site of minor atherosclerotic plaquing, in whom symptoms are severe and unrelieved by nitrates or dipyridamole, and with the threat of sudden dysrhythmic death, surgery may have a limited place.

Though the fully fledged Prinzmetal variant is rather rare, the concept of coronary spasm can probably be applied to more plebeian angina variants. Angina in the face of anatomically normal coronary arteries is more common in women than in men, and this may be due not to the frequency of female neurosis but to a greater propensity to arterial spasm. So called 
"Monday morning" angina in workers in nitroglycerin factories, attributed to nitrate withdrawal, possibly also derives from coronary spasm preventable or relieved by nitrates.

The Prinzmetal variant with ST elevation probably represents coronary spasm which lasts too little time to bring about infarction but too long to be associated with ST depression. ST elevation is known to be an early electrocardiographic event in patients who go on to develop frank changes of infarction, and it is probable that less or shorter lived spasm may be associated with more mundane E.C.G. changes of ischaemia, while even more prolonged spasm might cause infarction or death (with or without thrombosis at the site of spasm).

1 Prinzmetal, M., et al., American fournal of Medicine, 1959, 27, 375.

2 Silverman, M. S., and Flamm, M. D., Annals of Internal Medicine, 1971, $75,339$.

${ }^{3}$ Macalpin, R. N., Kattus, A. A., and Alvaro, A. B., Circulation, 1973, 47, 946.

4 Cheng, T. O., et al., Circulation, 1973, 47, 476.

5 Oliva, P. B., Potts, D. E., and Pluss, R. G., New England fournal of Medicine, 1973, 288, 745.

6 Rose, F. J., Johnson, A. D., and Carleton, R. A., Chest, 1974, 66, 719

7 Applefield, M. M., and Ronan, J. A., Chest, 1974, 66, 721.

8 Gaasch, W. H., et al., Chest, 1974, 66, 614.

9 Pachinger, O., and Judkins, M. P., European fournal of Cardiology, 1975, 2, 289.

\section{Operability of Lung Cancer}

Total resection is the treatment of choice for bronchial carcinoma, apart from cases of bronchoscopically diagnosed oat-cell carcinoma. ${ }^{1}$ However, total resection is found possible in only $20 \%$ or so of the patients diagnosed, ${ }^{2-5}$ and about onethird of those subjected to thoracotomy ${ }^{2}{ }^{6}$ are found to have a tumour which cannot be totally removed. Resection in these cases is only attempted if, as advocated by Abbey Smith, ${ }^{7}$ the surgeon believes in an aggressive policy of removing as much tumour as possible.

Where the tumour cannot be totally removed the survival rate is extremely poor. Belcher and Anderson ${ }^{8}$ found that resection had been possible in $79 \%$ of 1134 operations for carcinoma of the bronchus at the London Chest, the Middlesex, and Pinewood Hospitals from 1949 to 1963. The operative mortality had been $10 \%$ for resection and $4 \%$ for exploratory thoracotomy. The survival rate after resection was $46^{\circ} \%$ at two years. and $26 \%$ at five years, but only $3 \%$ of those patients who had had an exploratory thoracotomy were alive after two years. Weiss ${ }^{9}$ analysed a series of 968 men and 108 women who had operations for bronchogenic carcinoma from 1956 to 1965 at 12 teaching hospitals in Philadelphia. About one-third of the patients of both sexes had had exploration without resection; in these cases the operative mortality of $9.7 \%$ for men and $8.3 \%$ for women had been a risk incurred without benefit to the five-year post-thoracotomy survival rate of $2.4 \%$ for the men and nil for the women.

Unsuspected extension to the mediastinal lymph nodes and vascular invasion are the most likely reasons for a bronchial carcinoma to be found inoperable at thoracotomy, and methods of assessment likely to detect these conditions should be encouraged. Paulson and Urschel ${ }^{10}$ compared the effects of increased pretreatment investigation on 1135 patients with bronchogenic carcinoma seen from 1950 to 1959 and a further 952 patients seen from 1960 to 1969 . Their results showed that improved assessment of resectability led to a rise in the resection rate at thoracotomy from $75 \%$ to $91 \%$ and an increase in the five-year survival after thoracotomy from $18 \%$ to $35 \%$.

Extended radiographic techniques, including tomography in the anterior and lateral planes, may indicate the presence of enlarged tracheobronchial, subcarinal, or paratracheal lymph nodes, but it is unlikely to detect nodes less than $2 \mathrm{~cm}$ in diameter, and inf:ltrated lymph nodes smaller than that are all too frequently encountered at thoracotomy. Barium swallow may sometimes show enlarged subcarinal lymph nodes displacing or involving the oesophagus. Angiography has been reported as a valuable method of assessing whether major blood vessels have been invaded or compressed by enlarged lymph nodes, ${ }^{11} 12$ but the technique has so far been adopted as a routine preoperative investigation only in centres with adequate resources of equipment and personnel. Similar considerations limit the use of scintillation scanning of the lungs. ${ }^{13}$

Scalene node biopsy, first described by Daniels ${ }^{14}$ in 1949 , was extensively used during the 1950s to detect extrathoracic lymphatic spread. However, Morgan and Scott ${ }^{15}$ in a critical evaluation in 1962 pointed out that though scalene fat pad biopsies showed there was extrapulmonary extension in $12 \%$ of cases with non-palpable supraclavicular lymph nodes a negative biopsy did not indicate that the lesion was resectable.

Mediastinoscopy, introduced by Carlens ${ }^{16}$ in 1959, has now largely superseded scalene node biopsy except for palpably enlarged lymph nodes. Both sides of the mediastinum can be explored through the same incision, and specimens can be obtained from lymph nodes nearer to the carcinoma and therefore more likely to be affected. Pearson ${ }^{17}$ reported that $33 \%$ of a series of 239 patients with presumably operable bronchial carcinoma were proved by mediastinoscopy to have tumour in superior mediastinal lymph nodes. Similar results have been published by other investigators. ${ }^{18-21}$ In a series of 400 mediastinoscopies, including 296 patients with brenchial carcinoma, Sarin and Nohl-Oser ${ }^{22}$ found affected mediastinal lymph nodes in $35 \%$ of those with squamous cell carcinoma and $76 \%$ of those with oat-cell carcinoma. After exclusion from thoracotomy of those patients shown to have extension to the mediastinal lymph nodes, $94 \%$ of the remainder were found to have resectable growths. As an alternative to mediastinoscopy some thoracic surgeons prefer the greater exposure obtained by anterior mediastinotomy ${ }^{23}{ }^{21}$-at the expense of excision of costal cartilages; and in summary it seems that more routine use of one or other of these techniques could do much to reduce the number of patients with bronchial carcinoma found to be inoperable at thoracotomy.

${ }^{1}$ Fox, W., and Scadding, J. G., Lancet, 1973, 2, 63

Gifford, J. H., and Waddington, J. K. B., British Medical Fournal, 1957, $1,723$.

Barrett, R. J., et al., fournal of Thoracic and Cardiovascular Surgery, 1963, 46, 292.

4 Watson, W. L., and Schottenfeld, D., Diseases of the Chest, 1968, 53, 65.

5 Bignall, J. R., and Martin, M., Lancet, 1972, 2, 60.

Flavell, G., British Medical fournal, 1962, 1, 284.

Smith, R. Abbey, Thorax, 1970, 25, 62.

Belcher, J. R., and Anderson, R., British Medical fournal, 1965, 1, 948.

9 Weiss, W., American fournal of Surgery, 1974, 128, 799.

10 Paulson, D. L., and Urschel, H. C., Jr., fournal of Thoracic and Cardiovascular Surgery, 1971, 62, 554 .

11 Slesser, B. V., Britt, R. G., and Freer, J. L., Thorax, 1954, 9, 91.

12 Steinberg, I., and Finby, N., American Ұournal of Roentgenology, 1959, 81,

807.
13 Walker, R. H. Secker, and Provan, J. L., British Medical fournal, 1969, 3, 327.

14 Daniels, A. C., Diseases of the Chest, 1949, 16, 360.

15 Morgan, S. W., and Scott, S. M., Fournal of Thoracic and Cardiovascular Surgery, 1962, 43, 548.

${ }^{16}$ Carlens, E., Diseases of the Chest, 1949, 36, 343.

17 Pearson, F. G., Fournal of Thoracic and Cardiovascular Surgery, 1968, 55, 617.

${ }^{18}$ Maassen, W., Deutsche medizinische Wochenschrift, 1962, 87, 2004.

19 Reynders, H., Diseases of the Chest, 1964, 45, 606.

20 Gunstensen, J., and Wade, J. D., British fournal of Surgery, 1972, 59, 209.

21 Gibbons, J. R. P., British fournal of Diseases of the Chest, 1972, 66, 162.

22 Gibbons, J. R. P., British Fournal of Diseases of the Chest, 1972

23 Stemner, E. A., et al., fournal of Thoracic and Cardiovascular Surgery $1965,49,405$.

24 Evans, D. S., Hall, J. H., and Harrison, G. Kent, Thorax, 1973, 28, 444. 